\title{
INDOOR AIR QUALITY INDEX AND CHRONIC HEALTH DISEASE: A PILOT STUDY
}

\author{
Rajbala Soni ${ }^{1}$, Rajesh Dhankar ${ }^{2}$, Vikram Mor ${ }^{3}$ \\ ${ }^{1}$ Deptt.Of Environment Science Vaish College Of Engg., Rohtak \\ ${ }^{2}$ Deptt.Of Environment Science, Maharishi Dayanand University, Rtk, Haryana \\ ${ }^{3}$ Deptt.Of Environment Science,Maharishi Dayanand University, Rtk. Haryana
}

\begin{abstract}
Approximately about 2 million premature deaths per year in developing countries by indoor pollution this is estimated by WHO (2006). Indoor activities (cooking, smoking, incense, mosquitoes coil and others), building characteristics and outdoor climatic conditions have affected indoor air quality environment. Especially young and unemployed people spend about $90 \%$ of their times in indoor environment so, air quality index (AQI) is now becomes the essential task for determine the quality of indoor homes. Indoor air quality index concern to pollutant concentration. $A Q I=1 / 3[S P M / S S P M+S O 2 / S S O 2+N O x / S N O x] x 100$. More will be the value of AQI more hazardous will be the quality. One of the most important parameter for indoor air quality is particulate matter (PM2.5) and due to long exposure to particulate matters may lead to mortality. Women and children are mainly affected by indoor pollution because they spend more time in homes as compare to others. So, increased the respiratory symptoms, decreased the lung function, increased lung cancer incidence, cardiovascular mortality and accelerated artherosclerosis and vascular inflammation all these ill effects mainly observed in women's and infants.
\end{abstract}

Keywords: Indoor air quality, air quality index, vulnerable group, indoor pollution, acute respiratory infection.

\section{INTRODUCTION}

After rapid industrialization and urbanization indoor air quality becomes the challenge for all the developing and developed countries. In developing countries basically in rural areas, due to inefficient open fires, rural areas are highly exposed to high concentration of solid fuel smoke that is produced by burning of biomass and coal. Cow dung, wood, liquefied petroleum gas (LPG) and propane natural gas (PNG) kerosene are the main source for cooking purposes (Gautum et al.,2011 ). But in urban areas, there are other reasons like the poor sanitation, generation of solid wastes, open landfilling burning of solid waste, inadequate housing, lack of awareness regarding toxicity of air pollutants emitting from various sources and water supply causes the ill health effect of women and children (Bruce et. al.,2000). Combustion of biomass fuel in poorly ventilated kitchen leads to release of high concentration of respirable particulates, gases like $\mathrm{CO}, \mathrm{SO} 2$, NOx and toxic compounds benzene, formaldehyde and polycyclic aromatic compounds such as benzo (a) pyrene.

Indoor air quality environment is interacted and affected by the local outdoor air, specific building characteristics and indoor activities (Stranger et al.,2007). Indoor activities and poor ventilation qualities responsible for high level of indoor RSPM and PAHs in rural homes in india (Gadhkari 2008). Poor indoor air quality has been ranked as one of greatest health risk concern because people spends a substantial amount of time in indoor environment and indoor air concentrations of pollutants can be greatest than those found outdoors (Soysal and Demiral,2007). Indoor pollutants emissions originate not only from building materials or furnishing, but also from common household activities such as cooking, smoking and burning of incense and candles (Singh et al.,2012) and also from various consumer products which people use at their homes in their day to day activities.

\section{INDOOR AIR QUALITY AND AIR QUALITY}

\section{INDEX (AQI)}

ASHRAE define the air in which there are no known contaminants at harmful concentrations and where the substantial majority ( $80 \%$ or more) of the people exposed, do not express dissatisfaction. Indoor pollutant affects the quality of homes; there is an also indoor air quality standard that reflects quality of homes. AQI is calculated for four major air pollutants regulated by the Clean Air Act- Ground level Ozone, Particulate Pollution, Carbon Monoxide ,Sulfur dioxide .

Air Quality Index (AQI): The average of the sum of the ratios of three major pollutant concentrations to their respective air quality standard were obtained. The average was then multiplied by 100 to get the index [10].

$\mathrm{AQI}=1 / 3[\mathrm{SPM} / \mathrm{SSPM}+\mathrm{SO} / \mathrm{SSO} 2+\mathrm{NOx} / \mathrm{SNOx}] \mathrm{x} 100$ 
Where $\mathrm{S}_{\mathrm{SPM}}, \mathrm{S}_{\mathrm{SO} 2}$ and $\mathrm{S}_{\mathrm{NOx}}$ represent the ambient air quality standards for SPM, SO2 and NOx.

For each of these pollutants, EPA has established national air quality standards to protect public health. EPA is currently reviewing the national air quality standard for nitrogen dioxide. EPA (Environment Protection Agency) have recommended the scale to detect Air quality index. AQI starts from 0-500. More will be the value of AQI more unhealthy air and serious health effects.

\begin{tabular}{|l|l|l|}
\hline QUALITY & RANGE & STATUS OF AIR QUALITY \\
\hline Good & $0-50$ & $\begin{array}{l}\text { Air quality is satisfactory and } \\
\text { poses little or no health risk. }\end{array}$ \\
\hline Moderate & $51-100$ & $\begin{array}{l}\text { Range may pose a moderate } \\
\text { health concern for a very small } \\
\text { number of individuals }\end{array}$ \\
\hline $\begin{array}{l}\text { Unhealthy } \\
\text { for } \\
\text { sensitive gr. }\end{array}$ & $101-150$ & $\begin{array}{l}\text { Members of sensitive groups } \\
\text { may experience health effects, } \\
\text { but the general public is unlikely } \\
\text { to be affected }\end{array}$ \\
\hline Unhealthy & $151-200$ & $\begin{array}{l}\text { Members of sensitive groups } \\
\text { may experience health effects, } \\
\text { but the general public is unlikely } \\
\text { to be affected }\end{array}$ \\
\hline $\begin{array}{l}\text { Very } \\
\text { Unhealthy }\end{array}$ & $201-300$ & $\begin{array}{l}\text { Trigger a health alert, meaning } \\
\text { everyone may experience more } \\
\text { serious health effects. }\end{array}$ \\
\hline Hazardous & Over 300 & $\begin{array}{l}\text { Trigger health warnings of } \\
\text { emergency conditions. The entire } \\
\text { population is even more likely to } \\
\text { be affected by serious health } \\
\text { effect. }\end{array}$ \\
\hline
\end{tabular}

Refrence:www.sim-air.org

\section{FACTORS EFFECT INDOOR AIR QUALITY}

Indoor Combustion-Combustion is the most important sources of air pollution. Indoor combustion for cooking, lighting and heating has contributing to air pollution. Fuel combustion in kitchens is the most dominant source of indoor air pollution and can cause severe impact on health and environment. Indoor air pollution from solid fuels as one of top leading causes of global mortality and disease (Lopez et al.,2006). This based on the use of biomass and coal as cooking fuels in rural parts of developing countries. Unvented or incompletely vented combustion also occur to a substantial extent in economically developed countries. Such combustion has a demonstrated impact on indoor pollutant concentration and exposures.

\subsection{Cooking}

In united state and other developed countries, cooking causes air pollutant exposures that have potential public health significance. For example, the use of natural gas as a cooking fuel is associated with elevated indoor exposures to nitrogen dioxide, a byproduct of the combustion process. Exposure to ultrafine particles can be substantially increased by emissions from cooking ((Bhangar et al.,2011) .One half of the world's population is exposed to high concentrations of solid fuel smoke (biomass and coal) that are produced by inefficient open fires, mainly in the rural areas of developing countries. Concentrations of particulate matter in kitchens increase to the range of milligrams per cubic meter during cooking. Emissions of ultrafine particles are caused not only by combustion of cooking fuel but may also result from high temperatures associated with electric cooking elements (Wallace et al.,2008). Earlier studies also reported the emission of great concentrations of particulate matters from small scale biomass combustion process and their adverse health effects (Bologo et al., 2012; Gordon et al.,2007) . Studies have shown that PM10 concentrations range from 500-2000 $\mu^{3} \mathrm{gm}^{3}$ during cooking sessions in typical Indian households, which is several times the USEPA, standard of 24-hour average of 150 $\mu$ gm (Balakrishnan et al.,2002). Particles with diameter below 10microns (PM10) and particularly those less than 2.5 microns (PM2.5) are small enough to penetrate deeply into the lungs and appears to have greatest potential for damaging the health. There are numbers of report that depends on questionnaire for study the biomass smoke and its exposure to health. (Mahesh et al.,2013 ; Hashmi et al.,2013).

\subsection{Smoking}

Indoor smoking adversely affects indoor air quality and public health. Smoking indoors has a strong influence on indoor levels of the particulate matter (Nazaroff and Klepeis 2004, Hyland et al 2008). Environmental tobacco smoke is also an important cause of environmental exposure to certain hazardous air pollutants, including acryonitrile, 1,3-butadiene, acetalaldehyde, acrolein and formaldehyde (Nazaroff and Singh 2004). Evidence indicates that several severe adverse health impacts are associated with ETS exposure, including acute mycocardial infraction (Lightwood and Glantz 2009), lung cancer and a host of respiratory health problems in children . Singh et al (2010) have estimated that $7.6 \%$ of children in US are exposed to ETS in their own homes. Exposure to ETS occur not only in within the residence in which smoking occurs, but also, in the case of multifamily dwelling, in neighboring units (Bohac et al 2011).

\subsection{Space Heating}

Combustion for space heating is sometimes associated with substantial pollutant emission; especially because of relatively large amounts of fuel used for home heating as compared. Household use of kerosene heaters and fireplaces for heating was found to be associated with respiratory symptoms in nonsmoking women. Colberk (2010) studied the particulate matter concentration increased in indoor air in winter when 
occupants burns wood and coal to keep them warm, concentration of particulate matter depends on biomass fuel used, duration of cooking, degree of incomplete combustion and also ventilation.

\subsection{Incense and Mosquitoes Coils}

Indoor air pollution in dwelling areas is mainly due to emission from cooking, smoking, burning of mosquito's coils, cigarettes, incenses sticks and candles. By smoking of a single cigarettes about 10,000 and $40,000 \mathrm{mg}$ particulate matter are inhaled and by burning of one mosquito coil releases the same amount of PM2.5 mass as burning of 75137cigraettes. Mosquito coil also widely uses as a repellant in various Asian countries including China, India, Malaysia, Korea, Japan and Thailand. Major active components in mosquitoes coil are pyrethroids such as d-allethrin, esbiothrin, transfluthrin and metofluthrin. Liu et al., 2003 studied that all particles emitted from burning mosquitoes coil was fine, < $1 \mu \mathrm{m}$ in diameter most particles were in size range of 0.01 $0.1 \mu \mathrm{m}$ and $0.2-0.3 \mu \mathrm{m}$. Burning of incense, candles and mosquito coils is generally an incomplete combustion process. It is well known that it produces various kinds of air pollutants including particulate matter (PM), carbon monoxide (CO), nitrogen dioxide (NOX), volatile organic compounds (VOCs) and toxic metals. Smoke released from these activities contain significant amount of pollutant like Particulate Matter (PM), Polycyclic aromatic hydrocarbons (PAHS), Carbon monoxide (CO) and other toxic gases which are identified as potential carcinogens (Singh et al.,2010). In India and other countries indoor pollution is also with incense, candles and mosquitoes coil. The combustion of incense, wood, cigarette and candles is important or ever major sources of residential indoor particulate matter especially in the $2.5 \mu \mathrm{msize}$. The burning of incense could generate large quantities of PM, carcinogenic PAHs (Chiang et al., 2006) and CO .

\section{HEALTH IMPACTS OF INDOOR AIR POLLUTION}

Both indoor and outdoor pollution cause major environmental health problem in developed and developing countries .It comes from sources of dust, gases and smoke, and is generated mainly by human activities but also naturally. While the problem regarding outdoor air pollution has been well publicized for several decades, it is indoor air pollution that is causing the most recent concerns for obvious reasons. Lopez et al (2006) ranked 'indoor air pollution from solid fuels as one of the top ten leading causes of global mortality and diseases. Incense burning almost doubles the risk of developing squamous cell upper respiratory tract carcinomas including nasal /sinus, tongue, mouth and laryngeal. There was an increased risk both in smokers and in nonsmokers, pointing to an independent effect of incense smoke. Indoor air pollution is the risk factor for number of diseases and poor health of society. Several severe adverse health impacts are associated with ETS (Environment Tobacco Smoke) exposure, including acute myocardial infraction (Lightwood and Glantz 2009), lung cancer, and a host of respiratory health problems in children and asthma in nurseries and primary school children (Sousa et al.,2012).Exposure to ETS occurs not only within the residence in which smoking occurs, but also, in the case of multifamily dwelling, in neighboring units (Bohac et al 2011). Acute respiratory tract infection (ARI), chronic obstructive pulmonary disease (COPD), low birth weight, cataract, blindness are more common in poor urban people of these countries. Women and children spend most of their time in indoors and majorly effected.

\section{WOMEN AND CHILDREN HEALTH}

It is also estimated that 3.7 percent of overall burden of disease is only due to indoor smoke (WHO, 2005) and indoor air pollution is also responsible for 2 million deaths in developing countries and 4percent of global burden of diseases (Bruce et al., 2000). Women are the primary cooks and care taker for children in nearly all culture, so their children are prone to receive the greatest exposure to the smoke from solid fuel combustion. The exposure leads to higher risks for women as well as children (Dasgupta et al.,2004 ; WHO, 2007 ). Several researchers (Mirza et al.,2008), (Akhtar et al.,2007), (Lakshmi Singh et al.,2011) found a linkage between indoor smoke the exposure and increase the risk of respiratory tract infections and lung cancer among house wives (Dabral et al.,2012). In India, usually women spend their 3 to 7 hours near the stove for cooking and highly exposed during cooking (Singh and Parveen, 2010). About $50 \%$ of deaths from chronic obstructive pulmonary disease (COPD) in developing countires are attributed to exposure to biomass fuels smoke and $75 \%$ of these deaths are in women. Studies both in india and other countries has a significant association symptoms such as chronic cough, chronic phlegm and chronic respiratory disease such as chronic bronchitis, asthma, corpulmonale and to chronic respiratory failure (Mahesh et al.,2013) and adverse pregnancy outcomes (Behera et al.,2010 ). In India, prematurity and low birth weight (LBW) were the major cause of mortality among the neonates and increase an acute lower respiratory infection (ALRI) was major cause of mortality.

\section{CONCLUSIONS}

Increasing the standard of living, indoor air quality is effected and women's are the most vulnerable group which affected by number of disease. There are number of pollutants released by cooking, burning and other spiritual activities. There is now need to address the problems differentially. There are number of health problems like acute respiratory tract infection (ARI), chronic obstructive pulmonary disease (COPD), low birth weight, cataract, blindness are more common in poor urban people of countries for which the available evidence is very limited. Efforts should also be made to support emerging 
exposure-response relationships; particularly for common and serious health problems. Research should pay attention to the valid outcomes such as acute lower respiratory infections.

\section{REMEDIES}

Indoor air pollution has a major impact on health. Rapid urbanization, globalization and increasing population crisis but there are stress on the environment. So, strategic actions should be taken by all sectors otherwise problem worst the health of humans and problem will be hardest on the poor and vulnerable sections of population. There is need to address the problems differently. There are ways to iron out the situation and make a women's time in kitchen healthy and pleasurable. These interventions can occur on many fronts which include: clean and efficient cooking fuel (LPG, electricity), Improving cooking devices (stoves) providing more heat, less smoke and less fuel consumption, Improving living environment (ventilation through doors and windows, separate kitchen), Behavioral change (spending less time in kitchen, fuel drying, using pot lids, proper maintenance of stoves, keeping children away from smoke). Awareness towards the ill health effects of indoor air pollution and make the standards for indoor pollutants.

\section{REFRENCES}

[1] Akhtar T., Uah, Z, Khan M.H., and Nazli, R., 2007. Chronic bronchitis in women using solid biomass fuel in rural Peshawar, Pakistan. Chest 132, 1472-1475.

[2] Behera D, Aggarwal G.,2010. Domestic cooking fuel exposure and tuberculosis in Indian women. Indian $\mathbf{J}$ Chest Dis Allied Sci 139-143.

[3] Bhangar S, Mullen N A, Kreisberg N M, Hering S V and Nazaroff W W., 2011.Ultrafine particle concentrations and exposures in seven residences in northern California Indoor Air 21 132-144.

[4] Bohac D.L, M.J. Hewett, S.K. Hammond, and D.T. Grimsrud .,2011. Secondhand smoke transfer and reductions by air sealing and ventilation in multiunit buildings: PFT and nicotine verification. Indoor Air 21(1) 36-44.

[5] Bologa D.L, A. Paur, H. R., Seifer, H., Woletz K. and Ulbricht, T., 2012. Fine particle generation, evolution and control by small biomass combustion, Management of Environmental Quality: An International Journal, Vol.23, No.1, pp.36-55.

[6] Balakrishnan K., Sambandam, S., Ramaswamy, P., Mehta, S., Smith, K.R., 2004. Exposure assessment for respirable particulates associated with household fuel use in rural districts of Andhra Pradesh, India. Journal of Exposure Analysis and Environmental Epidemiology 14, S14-S25.

[7] Bruce, N., Perez-Padilla, R., Albalak, R., 2000. Indoor air pollution in developing countries: a major environmental and public health challenge. Bulletin of the World Health Organization 78, 1078-1092.

[8] Bruce, N. G., Boy E., and H. Delgado., 2002. Birth weight and Exposure to Kitchen Wood Smoke during Pregnancy. Environmental Health Perspectives, 110 (1), pp 109- 114.

[9] Colbeck I, Nasir Z.A, Ali Z., 2010.Characteristic environment of indoor /outdoor air pollution in urban and rural residential .Environment for Pakistan. Indoor Air 20,40-51.

[10] Dasgupta S., Huq M., Khaliquzzaman., M, Pandey K., Wheeler D., 2006. Indoor air quality for poor families: new evidence from Bangladesh. Indoor Air 16, 426-444.

[11] Dasgupta S., Huq M., Khaliquzzaman M., Pandey K., Wheeler D., 2004a. Who Suffers From Indoor Air Pollution? Evidences from Bangladesh. World Bank, pp. 1-23.

[12] Dabral S. Bhatt B., 2012 .Indoor Air Pollution Exposure and its Impact on Health. Indoor Air Journal of Ecology and Environmental Sciences, Volume 3, Issue 2, 2012, pp.-74-76.

[13] Stranger M., Potgieter-Vermaak S.S. and R. Van Grieken.,2007.Comparative overview of indoor air quality in Antwerp, Environ. Int., 33, 6.

[14] Stranger, M., Potgieter-Vermaak S.S. and R. Van Grieken .,2008. Characterization of indoor air quality in primary schools in Antwerp, Belgium, Indoor Air, $18,454-463$.

[15] Singh G K., Siahpush M and Kogan M D.,2010. Disparities in children's exposure to environmental tobacco smoke in the United States, 2007 Pediatrics 126, 4-13

[16] Soysal A and Demiral Y.,2007. Kapalı Ortam Hava Kirliliği (in Turkish), TSK Koruyucu Hekimlik Bülteni, 6, 221-226.

[17] Gordon J.K., Emmel N. D., Manaseki S. and Chambers., J., 2007. Perceptions of health effects of stoves in Mongolia. Journal of health Organization and Management, Vol.21 No.6,PP.580-587.

[18] Gadkari N., Pervez S.,2008. Source apportionment of personal exposure of fine particulates among school communities in India. Environmental Monitoring Assessment 142,227-241.

[19] Hashmi D.R , Shareef A , Abbasi F. A , Imtiaz Ahmed and Alia Bano Munshi ., 2013.Perception of female population health hazards associated with indoor air pollution in Karachi .Journal of Public Health and Epidemiology Vol. 3(4), pp. 93-100, April 2012.

[20] Singh A.B., Saleha Jamal.,2012. Assessing Vulnerability of Women to Indoor Air Pollution, Research Journal of Environmental and Earth Sciences 4(11): 982-989. 
[21] Lightwood JM., Glantz SA.,2009. Declines in acute myocardial infarction after smoke-free laws and individual risk attributable to secondhand smoke" Vol.120(14), pp1373-79.

[22] Lopez A.D., K.Shibuya., A.L.Hansell, L.S.Held,V.Schmid.,S.Buist.,2006. Chronic obstructive pulmonary disease:Current burden and future projections.Eur.Respir.J. pp.397-412.

[23] Mirza UK., Ahmed N., Majeed T.,2008. An overview of biomass energy utilization in Pakistan. Renew. Sustain. Energy Rev., 12, 1988-1996. Prianka, C., (2009) WHO guide on clean indoor air. Down To Earth, August 1631.

[24] Nazaroff W W., and Klepeis N E.,2004 Environmental tobacco smoke particles Indoor Environment: Airborne Particles and Settled Dust ed L Morawska and T Salthammer (Weinheim: Wiley-VCH) pp 245-74.

[25] Roy R.K. and Goel A.K., 2009. Indoor plants to combat indoor pollution. Science Reporter, pp 8-13.

[26] Kulshreshtha, P., Khare M., Seetharaman, P., 2008. Indoor air quality assessment in and around urban slums of Delhi city, India. Indoor Air 18, 488-498.

[27] Mahesh P. A., Jayaraj B. S., Prabhakar., S. K. Chaya and R. Vijaysimha.,2013. Identification of a threshold for biomass exposure index for chronic bronchitis in rural women of Mysore district, Karnataka, Indian J Med Res 137,pp 87-94.

[28] Pandey V.L., 2002). Daily average exposures to respirable particulate matter from combustion of biomass fuels in rural households of southern Indis," Environmental health Perspective, Vol.11 No.1, pp.1069-75.

[29] Singh A.L. and U. Parveen.,2010. Fuel Choice, Indoor Air Pollution and Women's Health: A Household Level Perspective. In: Singh, A.L. (Ed.), Environment and Health. B.R. Publishers, New Delhi, pp: 1-34.

[30] Wallace L., Wang F., Howard-Reed C and Persily A .2008. Contribution of gas and electric stoves to residential ultrafine particle concentrations between 2 and $64 \mathrm{~nm}$ : size distributions and emission and coagulation rates Environ. Sci. Technol. 42 8641-47.

[31] WHO (2000). Addressing the Links between Indoor Air Pollution, Household Energy and Human Health: Based on the WHO-USAID Global Consultation on the Health Impact of Indoor Air Pollution and Household Energy in Developing Countries (meeting report). Washington, DC.

[32] World Health Organization, 2005. Indoor Air Pollution and Health. Fact Sheet, No.292, June, Washington DC.

[33] WHO.,2007. Indoor Air Pollution: National Burden of Disease Estimates; WHO Press: Geneva, Switzerland, 2007.

[34] WHO.,2000. Indoor air pollution in developing countries: a major environmental and public health challenge. Bull. World Health Organ., 78(9): 10781092 